${ }^{1}$ School of Dentistry, University of Federal of Piaui, Teresina,

Piauí, Brazil.

${ }^{2}$ Department of Restorative Dentistry, School of Dentistry University of Federal of Piauí, Teresina, Piauí, Brazil

${ }^{3}$ School of Dentistry, University of São Paulo, São Paulo, Brazil

Corresponding author: Urias Silva Vasconcelos School of Dentistry, University of Federal of Piaui, Teresina, Piauí, Brazil.

Street Maestro Pedro Alcântara, no 4708, Jurema Park, Teresina, Piaui, Brazil.

Phone: +55 86 99419-2442

E-mail: urias.svasconcelos@gmail.com

Received: November 19, 2018

Accepted: June 02, 2019

\section{Effects of the combination of Er: YAG laser and sandblasting on the shear bond strength between zirconia and resin cement}

\author{
Urias Silva Vasconcelos ${ }^{1, *}$, Thalisson Saymo de \\ Oliveira Silva ${ }^{1}$, Daylana Pacheco da Silva ${ }^{1}$, Graciela \\ Maria Oliveira Sipaúba ${ }^{1}$, Valdimar da Silva Valente², \\ Raquel Virginia Zanetti ${ }^{3}$, Carmem Dolores Vilarinho \\ Soares de Moura ${ }^{2}$
}

Aim: This study was conducted to determine the bond strength between zirconia ceramic and resin luting cement according to the type of surface treatment applied. Methods: Sixty zirconia cylinders measuring $4 \times 4 \mathrm{~mm}$ were manufactured and distributed into five experimental groups and a control group ( $\mathrm{n}=10)$ : $\mathrm{G} 1$ - sandblasting with $110 \mu \mathrm{m}$ aluminum oxide; $\mathrm{G} 2$ - sandblasting with $30 \mu \mathrm{m}$ Rocatec Soft ${ }^{\oplus}$, G3 - Er:YAG laser irradiation at $400 \mathrm{~mJ}$; G4 - Er:YAG laser combined with sandblasting with aluminum oxide; G5 - Er:YAG laser combined with sandblasting with Rocatec Soft ${ }^{\circledR}$; $\mathrm{G} 6$ - no treatment (Control). The zirconia cylinders were bonded in the center of composite resin cylinders (6 $\mathrm{mm}$ diameter) using RelyX Ultimate ${ }^{\circledR}$ cement. Shear strength was measured after thermocycling (6000 cycles and 5-55 $\mathrm{C}$ ). Data were analyzed using one-way ANOVA and Tukey's post-hoc with a $5 \%$ significance level. Results: Group 4 had a significantly higher shear strength than all the other groups, except Group 1. Group 3 had a significantly lower shear strength compared

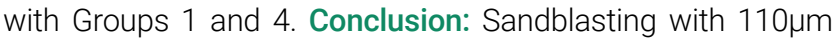
aluminum oxide particles after laser irradiation may be an effective zirconia surface treatment. The use of Er: YAG laser alone is not effective at increasing the bond between resin cement and zirconia.

Keywords: Zirconium. Laser therapy. Shear Strength. 


\section{Introduction}

Zirconium oxide has been used to manufacture crowns and fixed prosthesis infrastructures ${ }^{1}$ because of its aesthetics, biocompatibility and high mechanical strength ${ }^{2}$. It has a highly crystalline structure, which means it does not bond well with resin cement using standard techniques ${ }^{3,4}$. The luting of prostheses with this type of infrastructure is often carried out with conventional cements ${ }^{5}$.

Unlike many ceramics, zirconia consists mainly of crystals ${ }^{5}$. The absence of a glassy phase interferes with the effectiveness of adhesive cementation procedures, such as the use of hydrofluoric acid and silane ${ }^{1,3,6,7}$. Surface treatments and the use of materials that have a chemical compatibility with zirconia have been found to improve the strength of adhesive bonding 1,4,6,8.

The surface treatments of zirconia include sandblasting with aluminum oxide $\left(\mathrm{Al}_{2} \mathrm{O}_{3}\right)$, sandblasting with silica-coated (silicatization) $\mathrm{Al}_{2} \mathrm{O}_{3}{ }^{8-10}$, the use of a phosphate monomer primer (MDP), plasma spraying and the use of layers of a low melting point porcelain for subsequent acid etching 3,9,11,12. These treatments can increase the adhesive bond. However, few studies have assessed the durability of this bond after storage and/or thermocycling ${ }^{3}$. Sandblasting can cause flaws and defects that may compromise the mechanical properties and durability of crowns ${ }^{13,14}$.

Alternatives to zirconia surface treatment such as irradiation with high power lasers (Er: YAG, Nd: YAG and CO2) have also been recommended ${ }^{11,13,15-24}$. This treatment can increase the shear strength of the zirconia to resin cement ${ }^{15,25}$, however, it can cause microcracks that weaken the zirconia structure and impair adhesion ${ }^{26}$.

Studies using combinations of chemical and mechanical treatments of zirconia's surface have produced contradictory results ${ }^{25,27,28}$, and thus further studies are required. The purpose of this study was to analyze the effects of isolated and combined surface treatments of zirconia on the adhesive bond. The hypothesis tested was that the surface treatments do not alter the adhesive bond strength.

\section{Materials and methods}

Sixty $4 \times 4 \mathrm{~mm}$ cylinders were obtained from the milling of polycrystalline tetragonal zirconia stabilized with yttrium Y-TZP (ZrO2-Y2O3), and pre-sintered at $1,530^{\circ} \mathrm{C}$, following the manufacturer's instructions (ProtMat@ Advanced Materials, São Paulo, Brazil). The surface to be treated was polished with a double-sided diamond disc (Komet, São Paulo, Brazil) for 60 seconds under constant water cooling. After polishing, the cylinders were cleaned using ultrasound with isopropyl alcohol (99.8\%) for 5 minutes and stored in Petri dishes.

\section{Surface treatments}

The surfaces of the zirconia cylinders were treated using the following protocols: Group 1 - sandblasting with $110 \mu$ m aluminum oxide $\left(\mathrm{Al}_{2} \mathrm{O}_{3}\right)$ particles (Polidental ${ }^{\circledR}$ Ind. and Comercio Ltda, São Paulo, SP, Brazil) (Zhermack Technical S25R) at a distance of $10 \mathrm{~mm}$ perpendicular to the zirconia surface for 10 seconds and under 
2.8 bar pressure; Group 2 - sandblasting with Rocatec Soft ${ }^{\circledR} 30 \mu \mathrm{m}$ (3M ESPE, St. Paul, USA) for 20 seconds, following the same protocol as Group 1; Group 3 - Er:YAG laser irradiation (Smart Plus ${ }^{\circledR}$, Deka laser, Florence, Italy) $10 \mathrm{~mm}$ perpendicular to the surface of the zirconia for 15 seconds with air/water spray cooling (wavelength $2,940 \mathrm{~nm}, 400 \mathrm{~mJ}$ of energy intensity, power of $4.0 \mathrm{~W}$, pulse $100 \mu \mathrm{s}$ and frequency of $10 \mathrm{~Hz}$ ); Group 4 - Er: YAG laser irradiation with the same protocol as Group 3, followed by sandblasting with aluminum oxide $110 \mu \mathrm{m}$ as in Group 1; Group 5 - Er: -YAG laser irradiation with the same protocol as Group 3, followed by sandblasting with Rocatec Soft ${ }^{\circledR} 30 \mu \mathrm{m}$ as in Group 2; Group 6 - no surface treatment, only polishing and ultrasound cleaning (Control).

After the treatments, the cylinders were cleaned using ultrasound with $99.8 \%$ isopropanol for 5 minutes, dried in the open air and then stored in Petri dishes until the bonding procedure. The cylinders of groups 2 and 5 were not cleaned with ultrasound in order to avoid removal of the silica deposited on the surface.

\section{Scanning electron microscope analysis}

One specimen from each group was randomly selected for surface morphological analysis using a scanning electron microscope (Quanta Feg 250, FEl, USA, 5Kv). Photomicrographs were captured under 500x, 1000x, 3000x and 5000x magnification.

\section{Preparation of composites cylinders}

Composite cylinders (Filtek Z350 ${ }^{\circledR}$, 3M ESPE, USA) $10 \mathrm{~mm}$ thick $\times 6 \mathrm{~mm}$ in diameter were made using a transparent plastic tube, photoactivated for 30 seconds on all surfaces with LED light (Bluephase ${ }^{\circledR}$, Ivoclar Vivadent, Schaan, Liechtenstein), at $1200 \mathrm{~mW} / \mathrm{cm}^{2}$. After photoactivation, the plastic tube was removed and the cylindersphotoactivated again for 40 seconds. The surface of the cylinders was polished with SofLex ${ }^{\circledR}$ polishing discs used in decreasing order of granulation and then sandblasted with $30 \mu \mathrm{m}$ aluminum oxide particles for 10 seconds. The composite resin cylinders were placed in a matrix $15 \mathrm{~mm}$ thick by $20 \mathrm{~mm}$ in diameter and embedded in colorless chemically activated acrylic resin (JET, Clássico, Artigos Odontológicos, São Paulo, Brazil).

\section{Bonding Procedure}

For the bonding of the zirconia cylinders to the composite resin cylinders, Single Bond Universal ${ }^{\circledR}$ adhesive (3M, ESPE, USA) (with 10-MDP/silane) and RelyX ${ }^{\mathrm{TM}}$ Ultimate ${ }^{\circledR}$ cement (3M, ESPE, USA) were used following the manufacturer's recommendations. The zirconia cylinder was pressed with a finger on the composite resin cylinder and the cement excess was removed with a microbrush. Each surface of the cylinders was photoactivated for 30 seconds with an LED light Bluephase ${ }^{\circledR}$.

\section{Thermal cycling}

The specimens were stored for 24 hours at $37^{\circ} \mathrm{C}$ in distilled water. They were then submitted to 6,000 cycles $\left(5-55^{\circ} \mathrm{C}\right.$ ) (Thermal Cycle Machine, Mst CT-3, São Carlos, Brazil) for 30 seconds in each bath and 2 seconds of transition ${ }^{25}$. 


\section{Shear bond strength}

The shear strength test was performed in a mechanical testing machine (Emic, model DL $200{ }^{\circledR}$, Ribeirão Preto, São Paulo, SP, Brazil) with a knife-shaped device at a load of $50 \mathrm{Kgf}$ and a speed of $0.5 \mathrm{~mm} / \mathrm{min}$ applied at the interface of the zirconia-cement until fracture (Figure 1). The shear bonding strength in MPa was calculated by: F/A where: $F$ was the force applied ( $\mathrm{N})$; and $\mathrm{A}$, the area of bonding $\left(\mathrm{mm}^{2}\right)$, corresponding to $12.56 \mathrm{~mm}^{2}$.

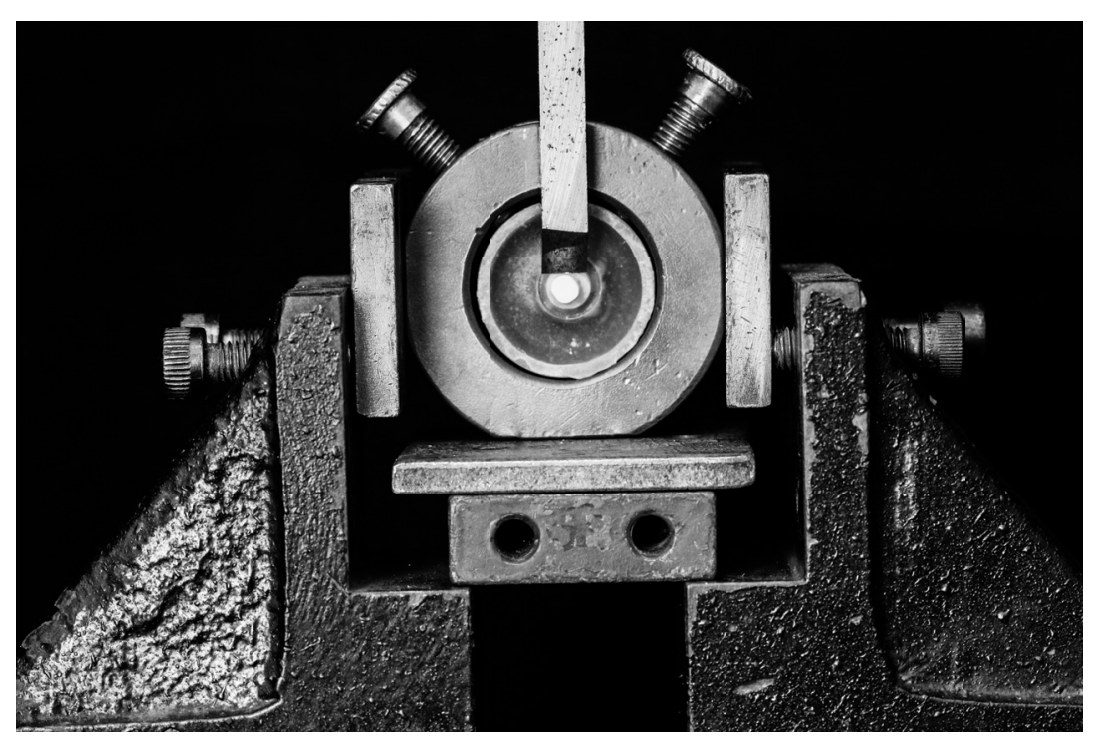

Figure 1. Shear bond strength test.

\section{Failure mode analysis}

A single examiner analyzed the images (Software Proscope HR, USA) of the fractured specimens using an optical microscope (Avantscope, USA) with a 50x magnification to identify whether the faults were adhesive (interface failure), cohesive (in resinous cement) or a combination of both types.

\section{Statistical Analysis}

The data were analyzed using SPSS Statistics software version 20.0 for Windows. The Kolmogorov-Smirnov test was applied to assess the distribution of data. Only one factor was involved in this study: the surface treatment of zirconia. Therefore, the data were analyzed using one-way ANOVA and the post hoc Tukey test to compare the means of the groups. Descriptive statistics were used to analyze the distribution of fracture types in the groups. A significance level of $a=.05$ was established.

\section{Results}

Morphological differences were observed after the surface treatments (Figure 2). The surface treated with aluminum oxide $110 \mu \mathrm{m}$ presented roughness throughout its 
length (Figure 2A). Rocatec soft $30 \mu \mathrm{m}$ promoted a smoother surface than aluminum oxide, but silica deposits were observed (Figure 2B) similar to Figure 2E. In Figure 2C, the laser created deep irregularities (scratches) on the surface; in addition, there were grooves that resulted from the polishing. The Er: YAG laser-treated surface followed by sandblasting with aluminum oxide particles $110 \mu \mathrm{m}$ presented several lines of microcracks and areas of depression (Figure 2D). The surface of the untreated (control) specimen had grooves that resulted from the polishing (Figure 2F).

ANOVA showed significant differences between the groups $(F=7.429, p<0.001)$. Group 4 was significantly different when compared with the Control group, but there
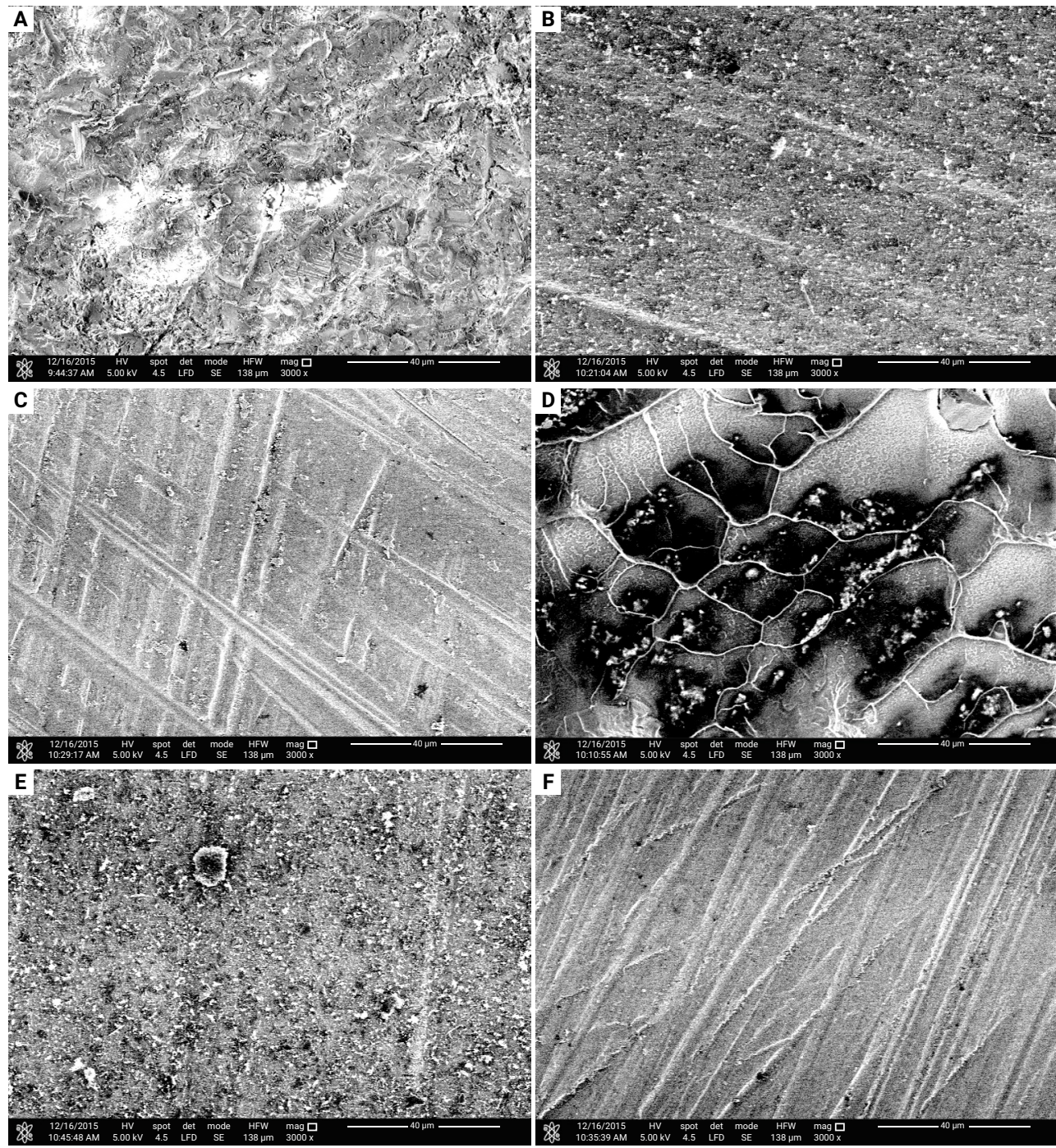

Figure 2. Scanning electron microscopy of treatments (3,000x magnification). 2A: sandblasting with $110 \mu \mathrm{m}$ aluminum oxide. 2B: sandblasting with Rocatec Soft@. 2C: Er: YAG laser irradiation. 2D: Er: YAG laser irradiation plus sandblasting with aluminum oxide $110 \mu \mathrm{m} .2 \mathrm{E}$ : Er: YAG laser plus sandblasting with Rocatec Soft ${ }^{\circledR}$. 2F: Control. 
was no difference when compared with Group 1. Group 3 was statistically different when compared with Groups 1 and 4 (Table 1).

Table 1. Mean shear strength (in MPa) of the groups after surface treatments.

\begin{tabular}{lll}
\hline Groups & Mean & SD \\
\hline Group 1 $\left(\mathrm{Al}_{2} \mathrm{O}_{3}\right)$ & $19.82^{\mathrm{b}, \mathrm{c}}$ & 5.94 \\
\hline Group 2 $\left(\right.$ Rocatec Soft $\left.{ }^{\oplus}\right)$ & $15.93^{\mathrm{a}, \mathrm{b}}$ & 4.79 \\
\hline Group 3 (Er:YAG laser) & $10.97^{\mathrm{a}}$ & 3.31 \\
\hline Group $4\left(\right.$ Er:YAG laser $\left.+\mathrm{Al}_{2} \mathrm{O}_{3}\right)$ & $23.12^{\mathrm{c}}$ & 3.40 \\
\hline Group 5 (Er:YAG laser + Rocatec Soft $\left.^{\circledast}\right)$ & $15.28^{\mathrm{a}, \mathrm{b}}$ & 5.46 \\
\hline Group $6($ Control) & $15.65^{\mathrm{a}, \mathrm{b}}$ & 4.21 \\
\hline
\end{tabular}

Different letters in the same column expressed a statistically significant difference (one-way ANOVA and Tukey's post-hoc, p<.05).

The most frequent type of failure was the mixed type (Groups 2, 3, 5 and 6) corresponding to $52 \%$ of the total, followed by cohesive and adhesive failures. There was no adhesive failure in the groups treated with sandblasting with $110 \mu \mathrm{m}$ aluminum oxide particles. In the group treated with Er: YAG laser followed by $110 \mu \mathrm{m} \mathrm{Al}_{2} \mathrm{O}_{3}$ sandblasting adhesive failures totalled $11 \%$, indicating that these surface treatments promoted a better adhesive bond (Table 2).

Table 2. Distribution of failure types between the groups.

\begin{tabular}{lccc}
\hline \multirow{2}{*}{ Groups } & \multicolumn{2}{c}{ Types of failure $\%$} \\
\cline { 2 - 4 } & Adhesive & Cohesive & Mixed \\
\hline 1 & 0 & 78 & 22 \\
\hline 2 & 33 & 11 & 56 \\
\hline 3 & 22 & 0 & 78 \\
\hline 4 & 11 & 67 & 22 \\
\hline 5 & 22 & 0 & 78 \\
\hline 6 & 44 & 0 & 56 \\
\hline
\end{tabular}

\section{Discussion}

The results demonstrated that the null hypothesis must be rejected. This study showed that the surface treatment may influence the adhesive bond. Since zirconia is a ceramic that should not be etched with hydrofluoric acid, treatments with aluminum oxide blasting can improve the strength of the bond with the resin cement, as demonstrated by the results of this study.

In this study, Er: YAG laser irradiation was performed before sandblasting with 110 $\mu \mathrm{m} \mathrm{Al}_{2} \mathrm{O}_{3}$ particles, because a decrease in adhesive strength when the reverse order 
is carried out has previously been shown ${ }^{25,27,28}$. The Er: YAG laser followed by sandblasting with $\mathrm{Al}_{2} \mathrm{O}_{3}$ significantly increased the zirconia/cement bond and reduced the occurrence of adhesive failures compared with the other treatments. This may have been a result of the presence of the irregularities (microcracks and grooves, as shownby SEM), caused by the combination of these two surface mechanical treatments. However, the effect of this combination on the mechanical properties of zirconia should be investigated, as studies have reported that Er:YAG laser can cause mild changes, cracking and even loss of zirconia material ${ }^{18,26,27,29}$. The adhesive strength increased when the zirconia surface was treated with $110 \mu \mathrm{m}$ aluminum oxide sandblasting only, which has also been observed in other studies ${ }^{18,27,28,30,31}$. The impact energy of the particles results in a rough and irregular surface throughout the extension of the zirconia surface, as the morphological analysis with SEM revealed, corroborating other studies ${ }^{11,21,23,26,28,30}$. Surface roughness improves adhesion due to increased surface area, reduction of surface tension and the promotion of mechanical retention ${ }^{11,25,32}$.

The irradiation of the Er: YAG laser showed low bond strength compared with the other experimental and control groups. This was probably a result of the lower roughness created by laser irradiation, especially when compared with sandblasting with $\mathrm{Al}_{2} \mathrm{O}_{3}$ and Rocatec. Similar results have previously been reported ${ }^{18,27,29,30,33,34}$. However, other studies have shown that laser irradiation increases the adhesive bond ${ }^{13,15,25}$. According to the authors, the irradiation of the laser promoted an increase of the surface roughness that, consequently, may have contributed to the increase of the micromechanical bonding ${ }^{13,15}$

In the present study, the group treated with sandblasting of $30 \mu \mathrm{m} \mathrm{Al} \mathrm{O}_{3}$ coated with silica (Rocatec Soft ${ }^{\circledR}$ ) did not result in a significant increase of the adhesive bond when compared to the Control, which corroborates the findings of Subasi and Inan ${ }^{27}$ who suggested that the silica coat did not result in a strong micromechanical or chemical interlocking with the resin cement. In contrast, significant improvements in bond strength between zirconia and resin cement have been reported in other studies when this treatment was used ${ }^{30,34}$.

Gomes et al. ${ }^{34}$ (2015) studied the effect of the Er: YAG laser followed by Rocatec $30 \mu \mathrm{m}$ and found no statistically significant increase in the adhesive bond compared to Rocatec ${ }^{\circledR}$ alone, a similar finding to that of our study. In both studies, the surfaces were treated in a similar manner, which may explain the results. Despite the laser changes to the zirconia surface, Rocatec ${ }^{\circledR}$ caused greater irregularities. Therefore, this combination of treatment is not effective in increasing the shear bond strength.

The types of failure observed in this study provided important data on the effectiveness of the different treatments, since the quality of the adhesive interface should also be taken into consideration. The groups treated with laser followed by sandblasting (Groups 1 and 4) presented cohesive and mixed failures, and cohesive failures within the resin cement were more frequent. Surface irregularities and micromechanical retention created by these treatments may have contributed to improved bond strength and a lower rate of adhesive failures. 
Studies in which the Er: YAG laser did not improve the bond strength reported high rates of adhesive failure ${ }^{19,25,27,30}$. In our study, laser irradiation with silica treatment and laser irradiation without silica treatment, presented similar failure rates (adhesive and mixed) with predominance of mixed failure (78\%). These treatments may not have promoted strong micromechanical or chemical retention, therefore resulting in adhesive failures.

In this study, the most frequent types of failures in the experimental groups were cohesive and mixed, which are clinically preferable to adhesive failure, because adhesive failure is usually associated with low adhesive strength ${ }^{35}$.

Within the limitations of this in vitro study, sandblasting with $110 \mu \mathrm{m} \mathrm{Al}_{2} \mathrm{O}_{3}$ particle after laser irradiation may be an effective zirconia surface treatment option. The Er: YAG laser used as an isolated treatment was not effective at increasing the shear strength. The Silica coated aluminum oxide (Rocatec ${ }^{a}$ ) did not improve the bond strength.

\section{Acknowledgements}

The authors are grateful to the Ribeirão Preto Dental School (USP) for having ceded their laboratory of mechanical tests and Professor Rogerio Romera for his collaboration in the development of the method of this study.

\section{Conflicts of interest}

The authors have no conflicts of interest relevant to this article.

\section{References}

1. Sadan A, Blatz M, Lang B. Clinical Considerations for Densely Sintered Alumina and Zirconia Restorations: Part 1. Int J Periodontics Restorative Dent. 2005 Jun;25(3):213-9.

2. Denry I, Kelly JR. State of the art of zirconia for dental applications. Dent Mater. 2008;24(3):299-3007. doi: 10.1016/j.dental.2007.05.007.

3. Blatz MB, Chiche G, Holst S, Sadan A. Influence of surface treatment and simulated aging on bond strengths of luting agents to zirconia. Quintessence Int. 2007;38(9):745-53.

4. Alghazzawi TF, Lemons J, Liu PR, Essig ME, Janowski GM. The failure load of CAD/CAM generated zirconia and glass-ceramic laminate veneers with different preparation designs. J Prosthet Dent. 2012 Dec;108(6):386-93. doi: 10.1016/S0022-3913(12)60198-X.

5. Koutayas SO, Vagkopoulou T, Pelekanos S, Koidis P, Strub JR. Zirconia in Dentistry: Part 2 Evidence-based clinical breakthrough. Eur J Esthet Dent. 2009;4(4): 348-80.

6. Blatz MB, Sadan A, Martin J, Lang B. In vitro evaluation of shear bond strengths of resin to densely-sintered high-purity zirconium oxide ceramic after long-term storage and thermal cycling. J Prosthet Dent. 2004;91(4):356-62.

7. Blatz MB, Sadan A, Kern M. Resin-ceramic bonding: a review of the literature. J Prosthet Dent. 2003 Mar;89(3):268-74.

8. De Castro HL, Corazza PH, Paes-Júnior TA, Della Bona A. Influence of Y-TZP ceramic treatment and different resin cements on bond strength to dentin. Dent Mater. 2012 Nov;28(11):1191-7. doi: 10.1016/j.dental.2012.09.003. 
9. May LG, Passos SP, Capelli DB, Ozcan M, Bottino MA, Valandro LF. Effect of silica coating combined to a MDP-based primer on the resin bond to Y-TZP ceramic. J Biomed Mater Res B Appl Biomater. 2010 Oct;95(1):69-74. doi: 10.1002/jbm.b.31684.

10. Souza RO, Valandro LF, Melo RM, Machado JP, Bottino MA, Ozcan M. Air-particle abrasion on zirconia ceramic using different protocols: effects on biaxial flexural strength after cyclic loading, phase transformation and surface topography. J Mech Behav Biomed Mater. 2013 Oct;26:155-63. doi: 10.1016/j.jmbbm.2013.04.018.

11. Usumez A, Hamdemirci N, Koroglu BY, Simsek I, Parlar O, Sari T. Bond strength of resin cement to zirconia ceramic with different surface treatments. Lasers Med Sci. 2013;28(1):259-66. doi: 10.1007/s10103-012-1136-x.

12. Kim MJ, Kim YK, Kim KH, Kwon TY. Shear bond strengths of various luting cements to zirconia ceramic: surface chemical aspects. J Dent. 2011;39(11):795-803. doi: 10.1016/j.jdent.2011.08.012.

13. Akin H, Tugut F, Akin GE, Guney U, Mutaf B. Effect of Er:YAG laser application on the shear bond strength and microleakage between resin cements and Y-TZP ceramics. Lasers Med Sci. 2012;27(2):333-8. doi: 10.1007/s10103-011-0883-4.

14. Kern M, Barloi A, Yang B. Surface conditioning influences zirconia ceramic bonding. J Dent Res. 2009 Sep;88(9):817-22. doi: 10.1177/0022034509340881.

15. Akın H, Ozkurt Z, Kırmalı O, Kazazoglu E, Ozdemir AK. Shear Bond Strength of Resin Cement to Zirconia Ceramic After Aluminum Oxide Sandblasting and Various Laser Treatments. Photomed Laser Surg. 2011 Dec;29(12):797-802. doi: 10.1089/pho.2011.3039.

16. Demir N, Subası MG, Ozturk N. Surface Roughness and Morphologic Changes of Zirconia Following Different Surface Treatments. Photomed Laser Surg. 2012;30(6):339-45. doi: 10.1089/pho.2011.3213

17. Ural C, Kalyoncuoglu E, Balkaya V. The effect of different power outputs of carbon dioxide laser on bonding between zirconia ceramic surface and resin cement. Acta Odontol Scand. 2012;70(6):541-6. doi: 10.3109/00016357.2011.600718.

18. Lin Y, Song X, Chen Y, Zhu Q, Zhang W. Effect of Er:YAG Laser Irradiation on Bonding Property of Zirconia Ceramics to Resin Cement. Photomed Laser Surg. 2013 Dec;31(12):619-25. doi: 10.1089/pho.2013.3489.

19. Kasraei S, Atefat M, Beheshti M, Safavi N, Mojtahedi M, Rezaei-Soufi L. Effect of Surface Treatment with Carbon Dioxide $\left(\mathrm{CO}_{2}\right)$ Laser on Bond Strength between Cement Resin and Zirconia. Lasers Med Sci. 2014;5(3):115-20.

20. Kasraei S, Rezaei-Soufi L, Heidari B, Vafaee F. Bond strength of resin cement to $\mathrm{CO}_{2}$ and Er:YAG laser-treated zirconia ceramic. Restor Dent Endod. 2014;39(4):296-302. doi: 10.5395/rde.2014.39.4.296.

21. Zanjani VA, Ahmadi H, Nateghifard A, Ghasemi A, Torabzadeh H, Tabrizi MA, et al. Effect of different laser surface treatment on microshear bond strength between zirconia ceramic and resin cement. J Investig Clin Dent. 2015 Nov;6(4):294-300. doi: 10.1111/jicd.12105.

22. Kirmali O, Akin H, Kapdan A. Evaluation of the surface roughness of zirconia ceramics after different surface treatments. Acta Odontol Scand. 2014 Aug;72(6):432-9. doi: 10.3109/00016357.2013.853320.

23. Arami S, Tabatabae MH, Namdar SF, Chiniforush N. Effects of different lasers and particle abrasion on surface characteristics of zirconia ceramics. J Dent. 2014;11(2):233-41.

24. Turp V, Akgungor G, Sen D, Tuncelli B. Evaluation of Surface Topography of Zirconia Ceramic After Er:YAG Laser Etching. Photomed Laser Surg. 2014;32(10):533-9. doi: 10.1089/pho.2014.3730.

25. Akyil MS, Uzun IH, Bayindir F. Bond Strength of Resin Cement to Yttrium-Stabilized Tetragonal Zirconia Ceramic Treated with Air Abrasion, Silica Coating, and Laser Irradiation. Photomed Laser Surg. 2010;28(6):801-8. doi: 10.1089/pho.2009.2697. 
26. Cavalcanti A, Pilecki P, Foxton R, Watson T, Tavares M, Gianinni M, et al. Evaluation of the surface roughness and morphologic features of Y-TZP ceramics after different surface treatments. Photomed Laser Surg. 2009;27(3):473-9. doi: 10.1089/pho.2008.2293.

27. Subaşi MG, İnan O. Influence of surface treatments and resin cement selection on bonding to zirconia. Lasers Med Sci. 2014;29(1):19-27. doi: 10.1007/s10103-012-1221-1.

28. Yenisey M, Dede D, Rona N. Effect of surface treatments on the bond strength between resin cement and differently sintered zirconium-oxide ceramics. J Prosthodont Res. 2016 Jan;60(1):36-46. doi: 10.1016/j.jpor.2015.09.001.

29. Cavalcanti AN, Foxton RM, Watson TF, Oliveira MT, Giannini M, Marchi GM. Bond Strength of Resin Cements to a Zirconia Ceramic with Different Surface Treatments. Oper Dent. 2009;34(3):268-75. doi: 10.2341/08-80.

30. Erdem A, Akar GC, Erdem A, Kose T. Effects of Different Surface Treatments on Bond Strength Between Resin Cements and Zirconia Ceramics. Oper Dent. 2014;39(3):118-27. doi: 10.2341/12-420-L.

31. Blatz MB, Phark JH, Ozer F, Mante FK, Saleh N, Bergler M, et al. In vitro comparative bond strength of contemporary self-adhesive resin cements to zirconium oxide ceramic with and without air-particle abrasion. Clin Oral Investig. 2010;14(2):187-92. doi: 10.1007/s00784-009-0278-0.

32. Amaral R, Ozcan M, Valandro LF, Balducci I, Bottino MA. Effect of conditioning methods on the microtensile bond strength of phosphate monomer-based cement on zirconia ceramic in dry and aged conditions. J Biomed Mater Res B Appl Biomater. 2008 Apr;85(1):1-9.

33. Foxton RM, Cavalcanti AV, Nakajima M, Pilecki P, Sherriff M, Melo L, et al. Durability of resin cement bond to alumina oxide and zirconia ceramics after air abrasion and laser treatment. J Prosthodont. 2011 Feb;20(2):84-92. doi: 10.1111/j.1532-849X.2010.00678.x.

34. Gomes AL, Ramos JC, Riego SS, Montero J, Albaladejo A. Thermocycling effect on microshear bond strength to zirconia ceramic using Er:YAG and tribochemical silica coating as surface conditioning. Lasers Med Sci. 2015;30(2):787-95. doi: 10.1007/s10103-013-1433-z.

35. Toledano M, Osori R, Osorio E, Aguilera FS, Yamauti M, Pashley DH, et al. Durability of resin-dentin bonds: effects of direct/indirect exposure and storage media. Dent Mater. 2007;23(7):885-92. 